\title{
Aluminum Activation
}

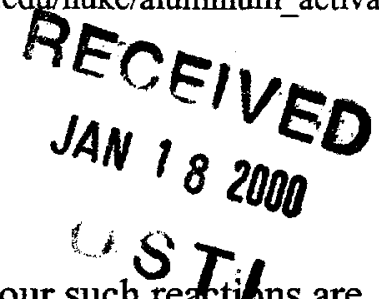

Neutron activation of aluminum may occur by several neutron capture reactions. Four such reati ns are described here: $\left.{ }^{27} \mathrm{Al}+\mathrm{n}={ }^{28} \mathrm{Al},{ }^{27} \mathrm{Al}(\mathrm{n}, \alpha)\right)^{24} \mathrm{Na},{ }^{27} \mathrm{Al}(\mathrm{n}, 2 \mathrm{n}){ }^{26} \mathrm{Al}$ and ${ }^{27} \mathrm{Al}(\mathrm{n}, \mathrm{p}){ }^{27} \mathrm{Mg}$. The radioactive nuclei ${ }^{28} \mathrm{Al},{ }^{24} \mathrm{Na}$, and ${ }^{27} \mathrm{Mg}$, which are produced via the ${ }^{27} \mathrm{Al}+\mathrm{n}={ }^{28} \mathrm{Al},{ }^{27} \mathrm{Al}(\mathrm{n}, \alpha){ }^{24} \mathrm{Na}$ and ${ }^{27} \mathrm{Al}(\mathrm{n}, \mathrm{p}){ }^{27} \mathrm{Mg}$ neutron reactions, beta decay to excited states of ${ }^{28} \mathrm{Si},{ }^{24} \mathrm{Mg}$ and ${ }^{27} \mathrm{Al}$ respectively. These excited states then emit gamma rays as the nuclei de-excite to their respective ground states.

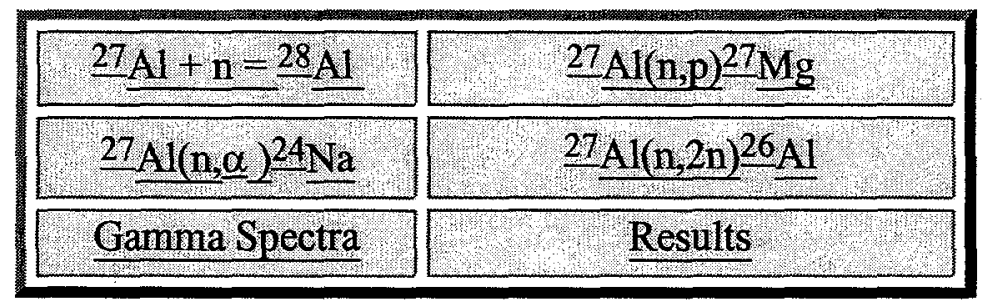

Neutron energies $\mathrm{E}_{\text {thermal }} \sim .025 \mathrm{eV} \mathrm{E} \mathrm{E}_{\text {slow }} \sim 1 \mathrm{keV} \mathrm{E}_{\text {fast }} \sim 100 \mathrm{keV}-10 \mathrm{MeV}$ 


\section{DISCLAIMER}

This report was prepared as an account of work sponsored by an agency of the United States Government. Neither the United States Government nor any agency thereof, nor any of their employees, make any warranty, express or implied, or assumes any legal liability or responsibility for the accuracy, completeness, or usefulness of any information, apparatus, product, or process disclosed, or represents that its use would not infringe privately owned rights. Reference herein to any specific commercial product, process, or service by trade name, trademark, manufacturer, or otherwise does not necessarily constitute or imply its endorsement, recommendation, or favoring by the United States Government or any agency thereof. The views and opinions of authors expressed herein do not necessarily state or reflect those of the United States Government or any agency thereof. 


\section{DISCLAIMER}

Portions of this document may be illegible in electronic image products. Images are produced from the best available original document. 
Neutron Capture

$$
{ }^{27} \mathrm{Al}+\mathrm{n}={ }^{28} \mathrm{Al}
$$

Neutron activation of ${ }^{27} \mathrm{Al}$ forming ${ }^{28} \mathrm{Al}$ which beta decays to ${ }^{28} \mathrm{Si}^{*}$ which subsequently de-excites via gamma emission to ${ }^{28} \mathrm{Si}$ is shown below schematically. Note: this reaction has a large thermal neutron capture cross section of $\sim 12$ barns.

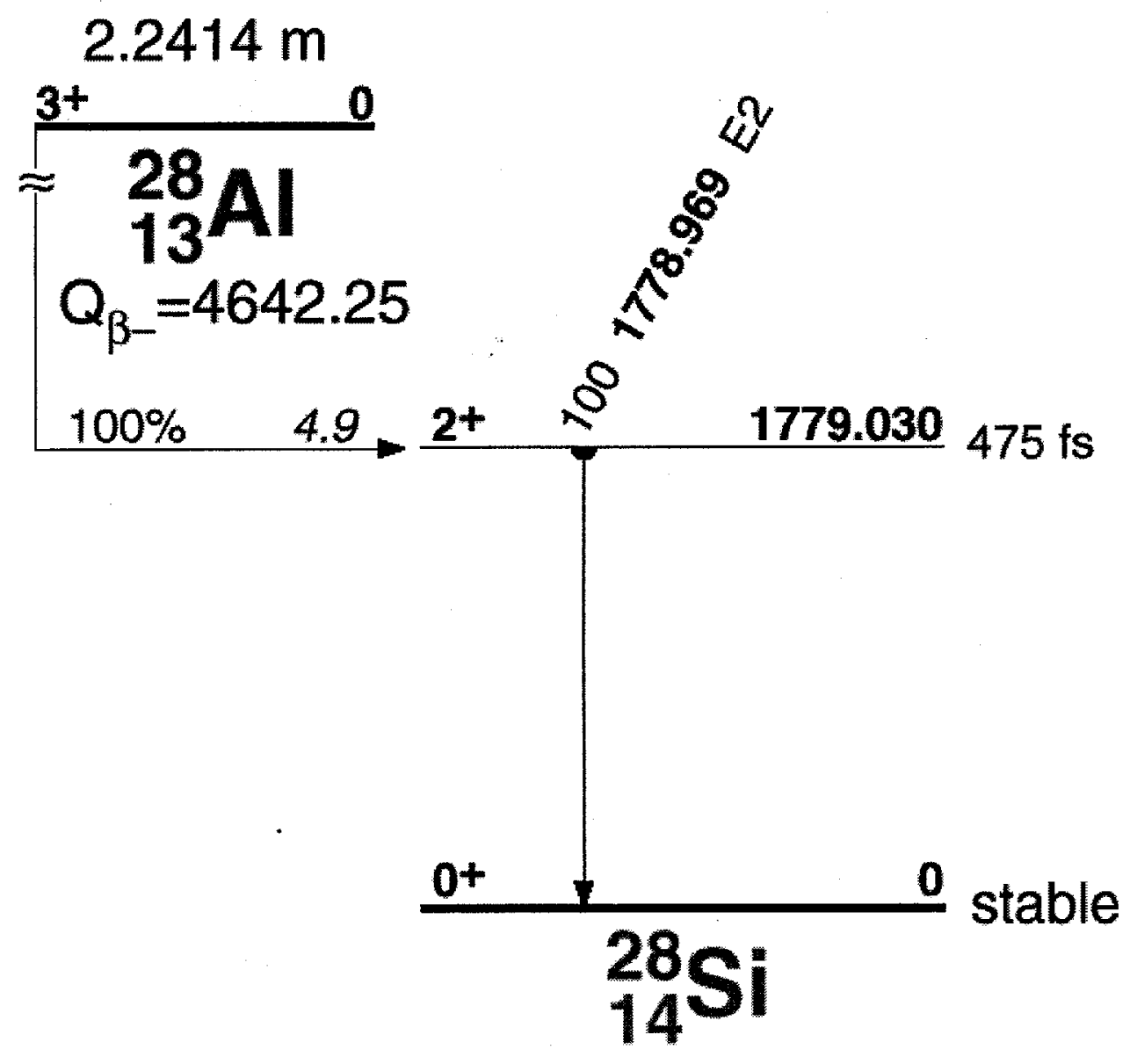




\section{$\left.{ }^{27} \mathrm{Al}(\mathrm{n}, \alpha)\right)^{24} \mathrm{Na}$}

The ${ }^{27} \mathrm{Al}(\mathrm{n}, \alpha)^{24} \mathrm{Na}$ reaction and decay scheme are shown below. The ${ }^{24} \mathrm{Na}$ beta decay feeds into the second excited state of ${ }^{24} \mathrm{Mg} 99.944 \%$ of the time. The transition from the second to the first excited state of ${ }^{24} \mathrm{Mg}$ emits a $2.754 \mathrm{MeV}$ gamma ray $99.944 \%$ of the time. Subsequently, the first excited state de-excites $100 \%$ of the time to the ground state, emitting a $1.368 \mathrm{MeV}$ gamma ray making this transition a good indicator of the measure of activation of the aluminum sample.

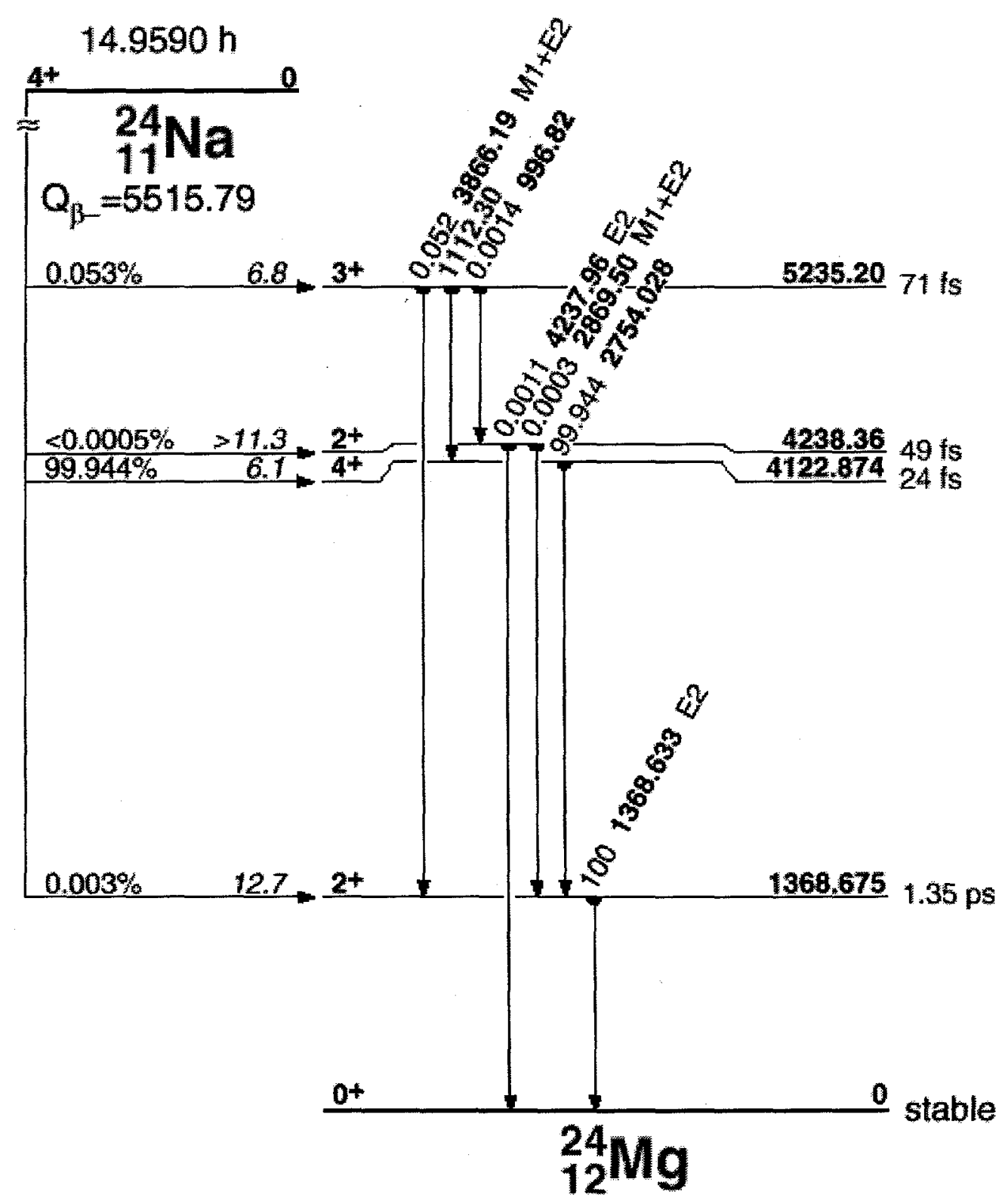




\section{${ }^{27} \mathrm{Al}(\mathrm{n}, \mathrm{p})^{27} \mathrm{Mg}$}

Shown below is the ${ }^{27} \mathrm{Al}(\mathrm{n}, \mathrm{p})^{27} \mathrm{Mg}$ reaction and decay scheme. In this reaction a proton is produced promptly after the neutron capture leaving ${ }^{27} \mathrm{Mg}$. The beta decay of ${ }^{27} \mathrm{Mg}$ feeds the first and second excited states of ${ }^{27} \mathrm{Al}$. These states de-excite and emit 0.843 and $1.014 \mathrm{MeV}$ gamma rays with branching fractions of $71 \%$ and $29 \%$ respectively.

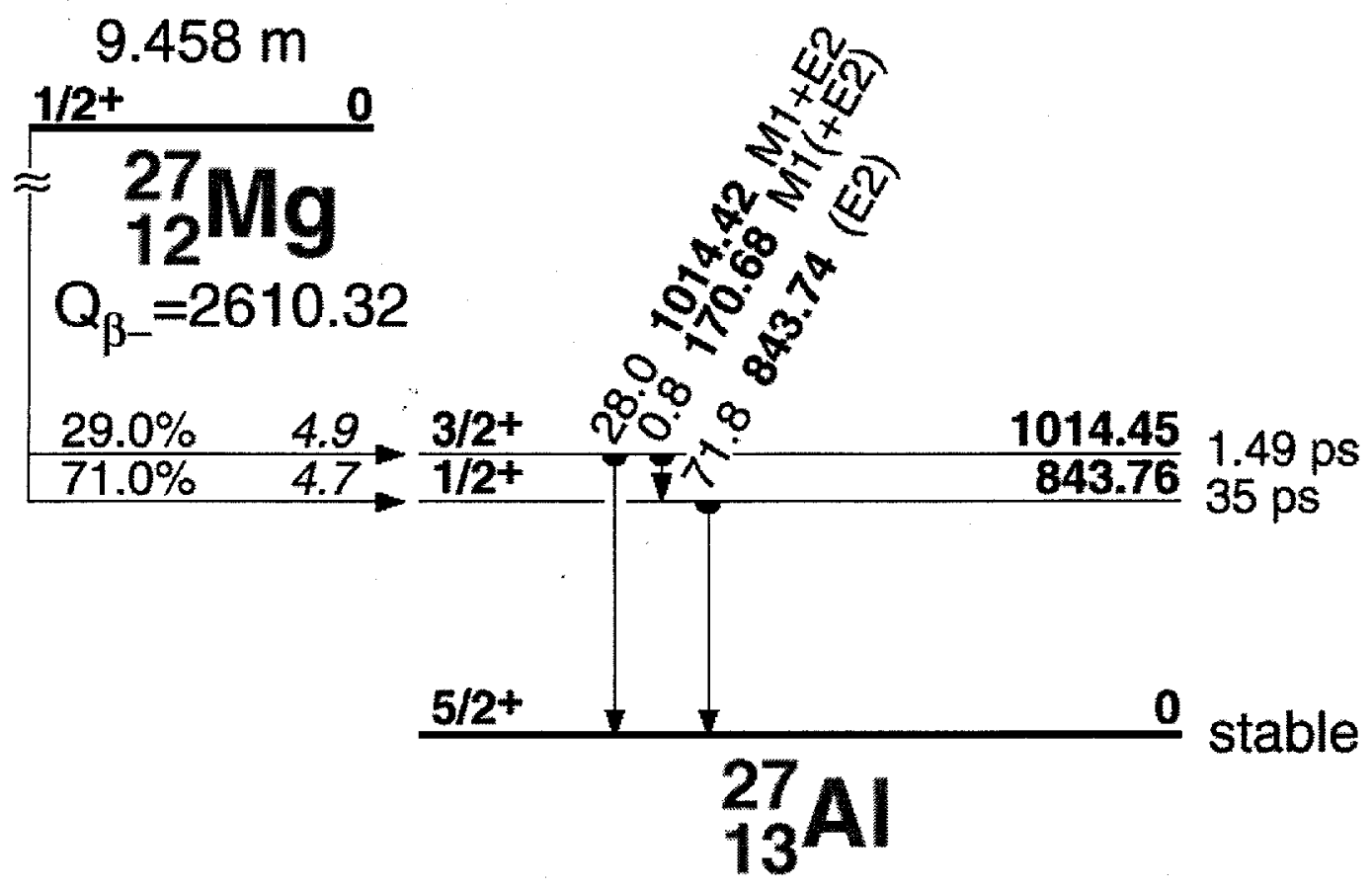




\section{${ }^{27} \mathrm{Al}(\mathrm{n}, 2 \mathrm{n}){ }^{26} \mathrm{Al}$}

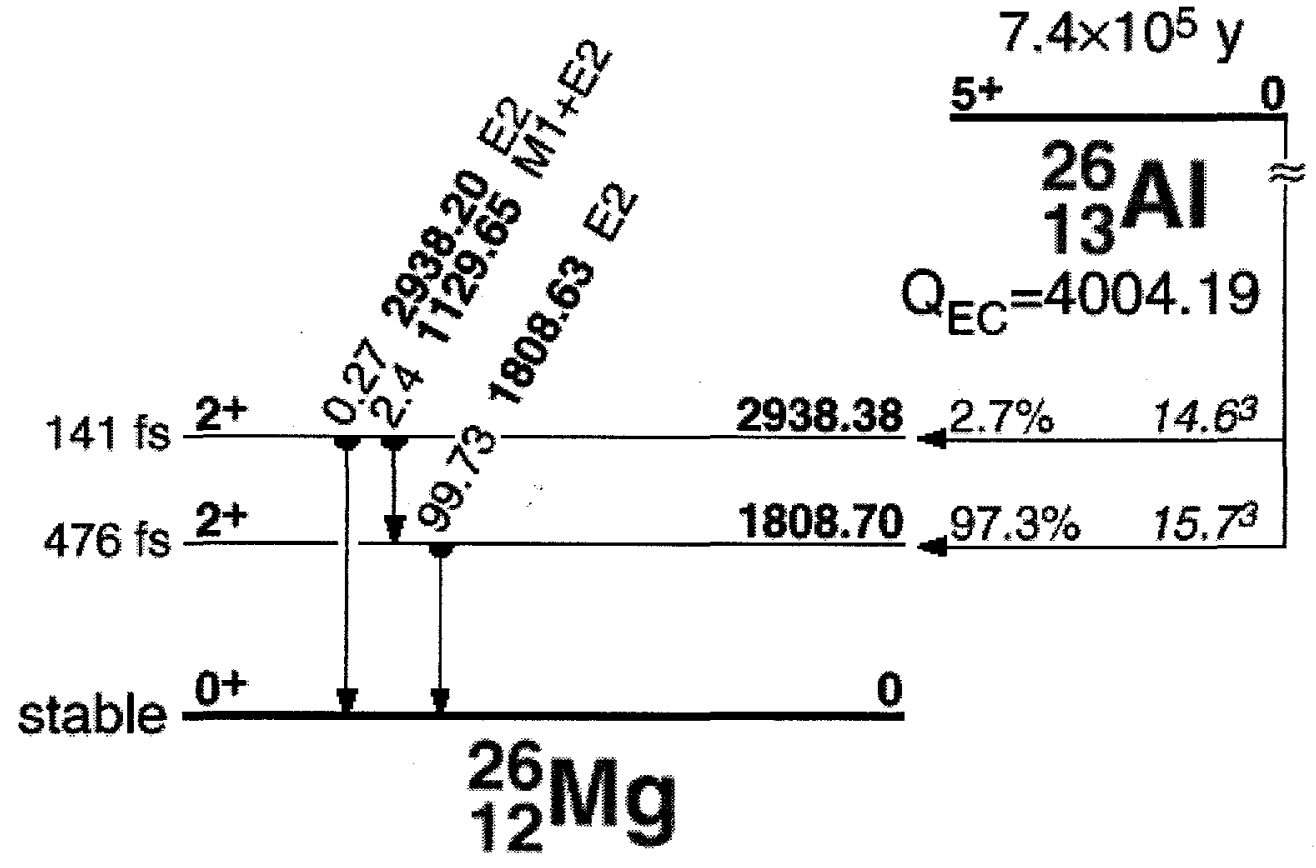




\section{Gamma Ray Spectra}

An aluminum sample was bombarded with mono energetic $14.1 \mathrm{MeV}$ neutrons. The resulting gamma ray spectrum was obtained by a High Purity Germanium (HPGe) detector after the activation and is shown below.

\section{Gamma ray spectrum}

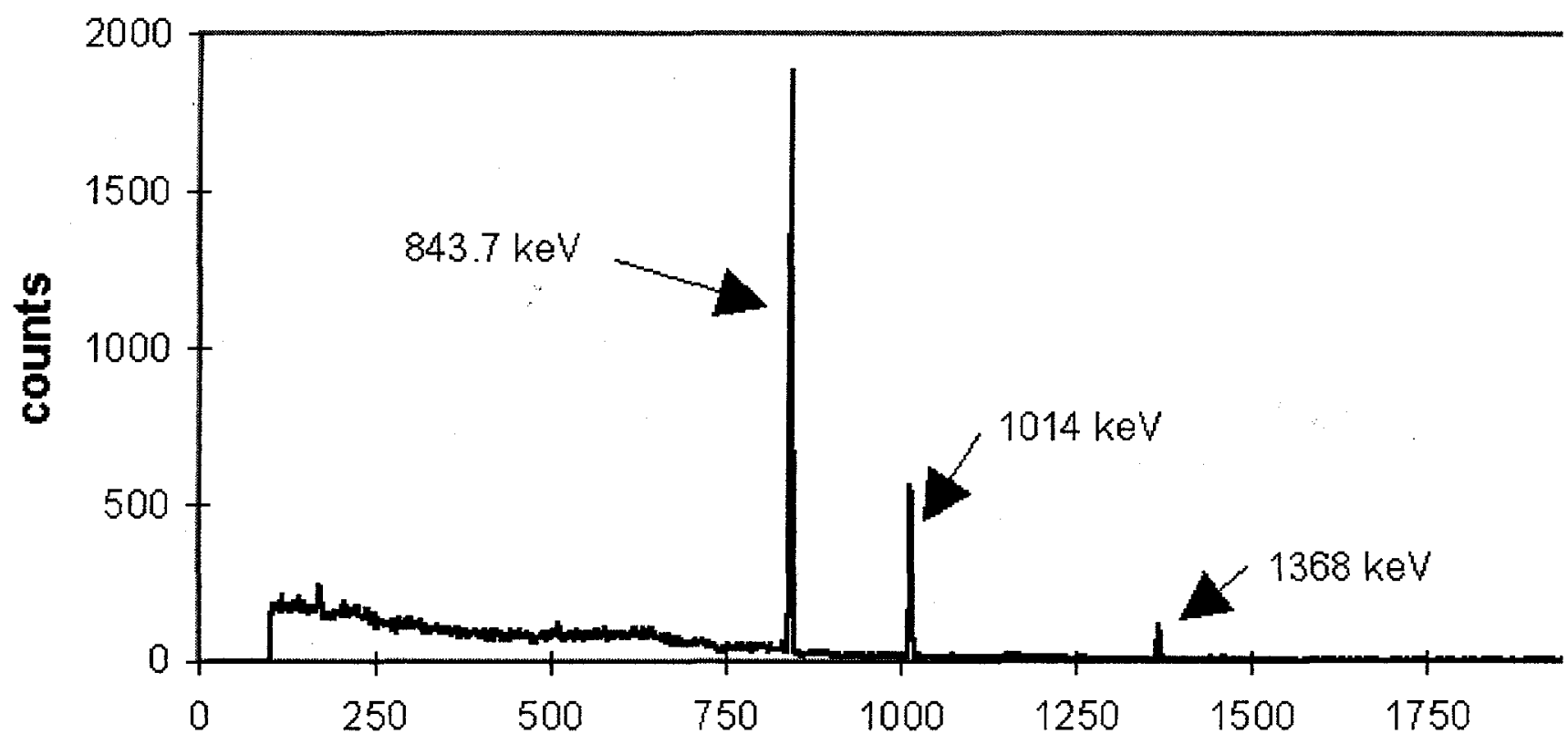




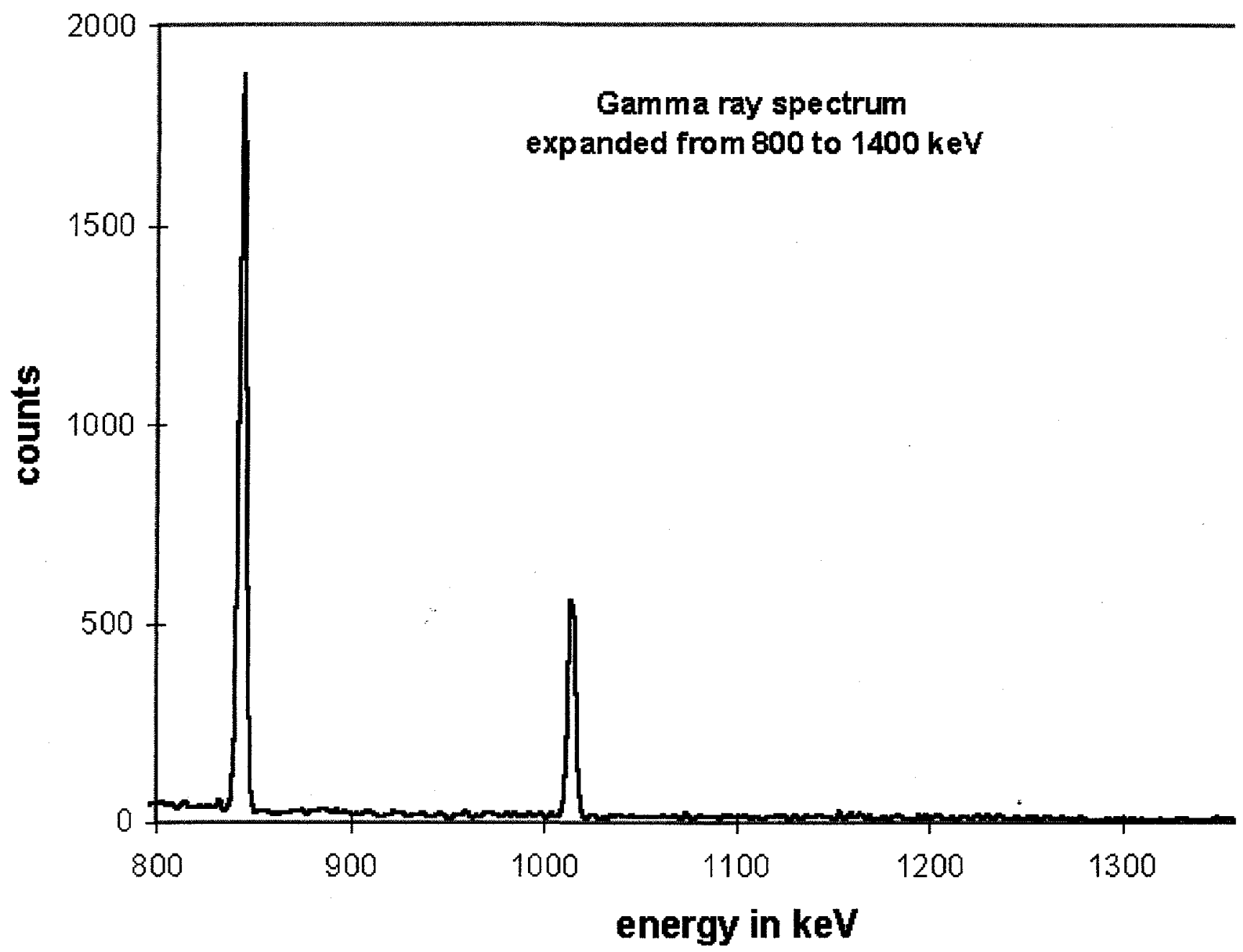

Note that there is no $1779 \mathrm{keV}$ peak produced by the ${ }^{27} \mathrm{Al}+\mathrm{n}={ }^{28} \mathrm{Al}$ capture reaction. However, peaks from the $\left.{ }^{27} \mathrm{Al}(\mathrm{n}, \alpha)\right)^{24} \mathrm{Na}$ and ${ }^{27} \mathrm{Al}(\mathrm{n}, \mathrm{p})^{27} \mathrm{Mg}$ reactions are easily seen in the HPGe detector spectrum.

In general, the number the gamma rays emitted by the activated aluminum sample is determined by several factors. Some of the factors are fixed by nature, such as the reaction, the neutron capture cross section, the half life, the efficiency of the detector, and the branching ratio of the gamma ray transitions in the decay products. Others may be changed in the experiment, such as the radial position of the sample from the neutron source, the mass of the activation sample and the counting time. The neutron capture threshold energy is another important factor. In the ${ }^{27} \mathrm{Al}(\mathrm{n}, \alpha){ }^{24} \mathrm{Na}$ and ${ }^{27} \mathrm{Al}(\mathrm{n}, \mathrm{p}){ }^{27} \mathrm{Mg}$ reactions thermal or low energy neutrons do not activate the sample. While in the ${ }^{27} \mathrm{Al}+\mathrm{n}={ }^{28} \mathrm{Al}$ capture reaction the cross section is large (12 barns!) for thermal neutrons. Hence the peak is seen in the NaI detector spectrum and not the HPGe detector spectrum. Shown below are plots of the neutron capture cross sections for the ${ }^{27} \mathrm{Al}(\mathrm{n}, \alpha)^{24} \mathrm{Na}$ and ${ }^{27} \mathrm{Al}(\mathrm{n}, \mathrm{p})^{27} \mathrm{Mg}$ reactions.

The NaI detector spectrum shown below was produced using a NaI detector measuring gamma rays emitted by an activated aluminum sample (note the reduced resolution of the $\mathrm{NaI}$ detector compared to the HPGe detector). 


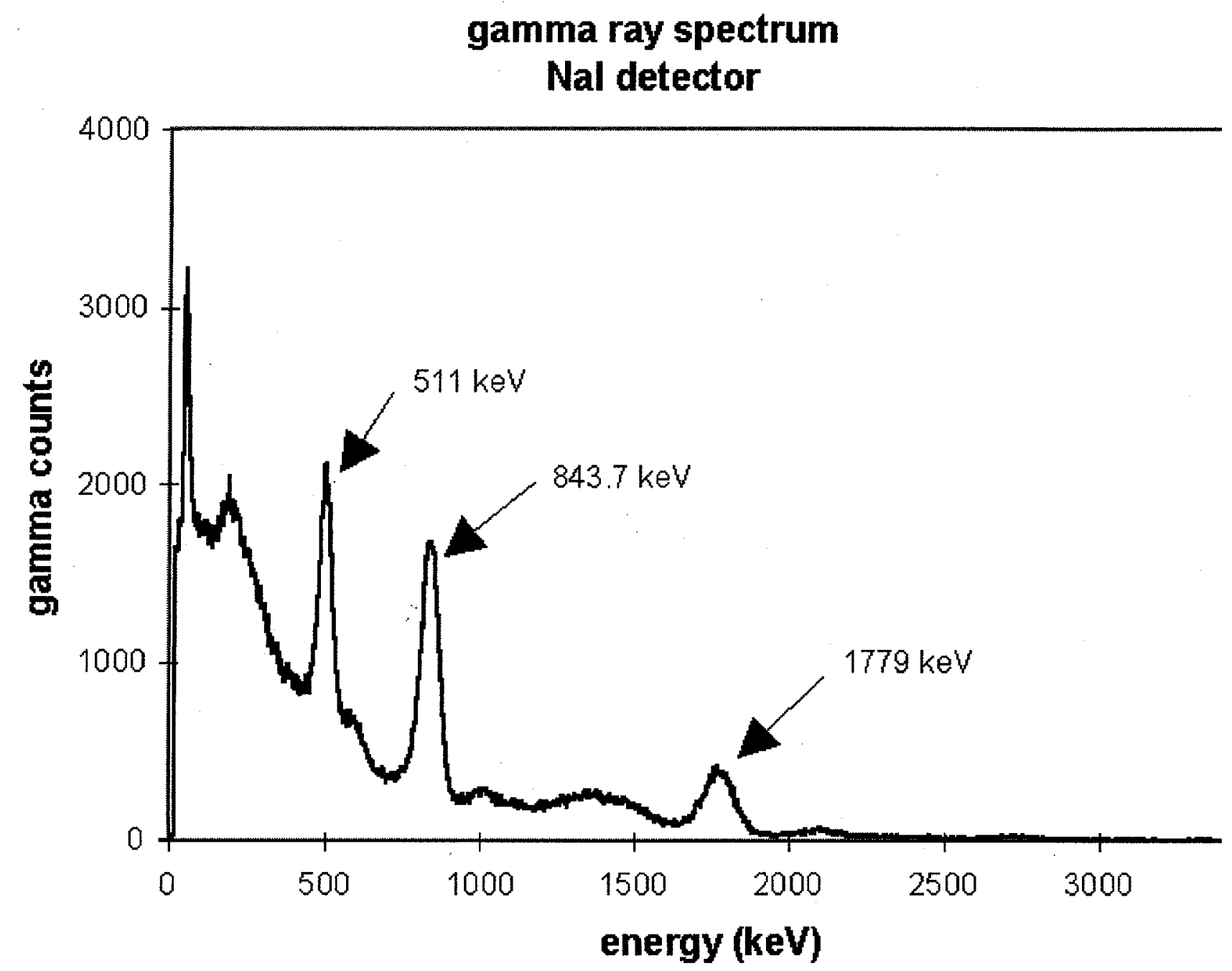

neutrons produced from a $\mathrm{PuBe}$ (plutonium-beryllium) source. (This is unlike the monoenergetic14.1 $\mathrm{MeV}$ neutron activation resulting in the HPGe detector spectrum). The PuBe source produces neutrons ranging in energy from $.025 \mathrm{eV}$ (thermal neutrons) to $11 \mathrm{MeV}$ neutrons (shown on the next page). The $\mathrm{PuBe}$ source was immersed in water which thermalized the higher energy neutrons, and further increased the likelihood of the ${ }^{27} \mathrm{Al}+\mathrm{n}={ }^{28} \mathrm{Al}$ capture reaction. This occurs because the ${ }^{27} \mathrm{Al}+\mathrm{n}={ }^{28} \mathrm{Al}$ reaction has a large thermal neutron cross section. Thus the $1779 \mathrm{keV}$ peak produced by this capture reaction is seen in the NaI detector spectrum and not in the HPGe detector spectrum. 


\section{PuBe Neutron Spectrum}

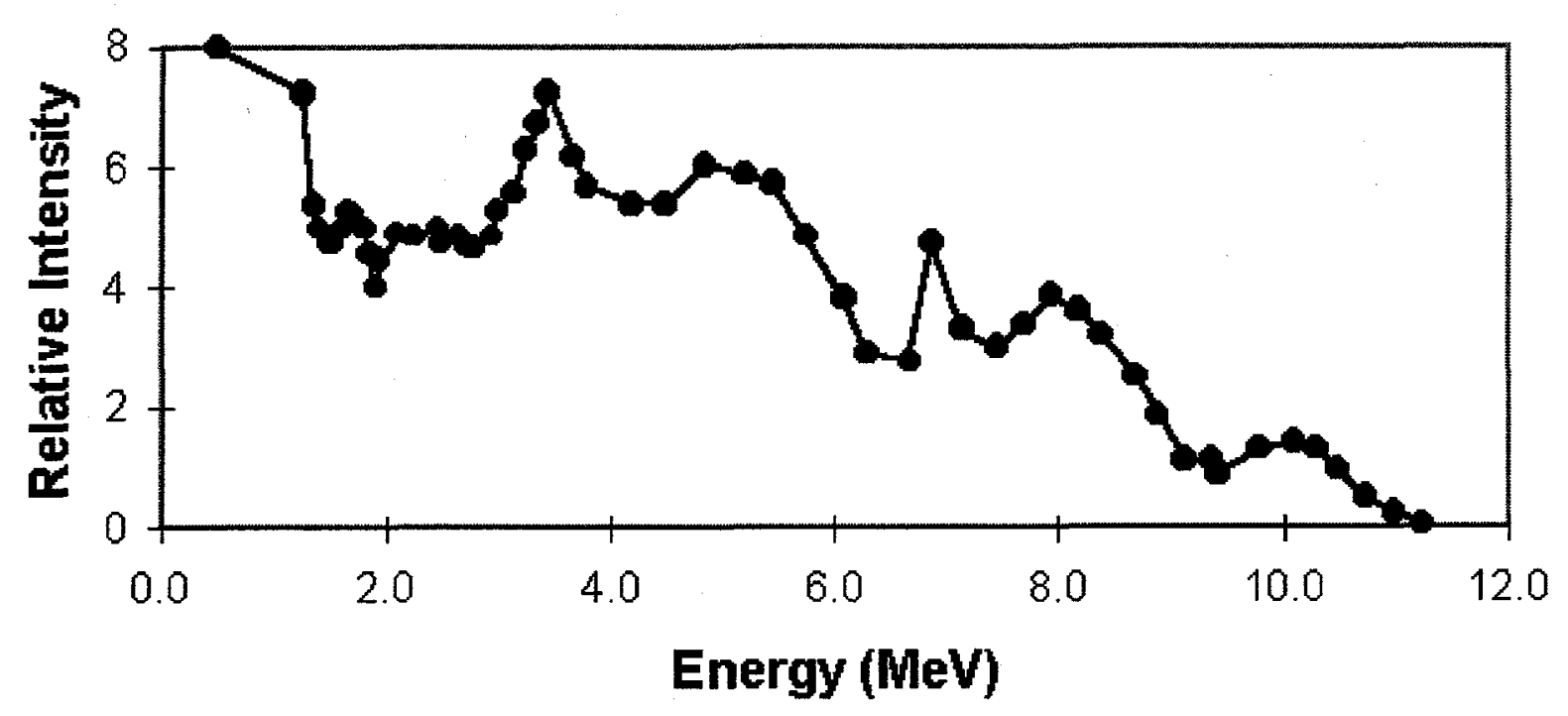




\section{DT neutron yield measurements using neutron activation of aluminum.}

\section{Stephen Padalino, Heather Oliver and Joel Nyquist}

\section{LLE Collaborators: Vladimir Smalyuk and Nancy Rogers}

The primary neutron yield, for more than 40 ICF shots, was determined by measuring the activity of an aluminum sample activated by DT neutrons. The reuslts were compared to the existing copper activation method. The radioactive nuclei ${ }^{24} \mathrm{Na}$ and ${ }^{27} \mathrm{Mg}$, which were produced via the ${ }^{27} \mathrm{Al}(\mathrm{n}, \alpha){ }^{24} \mathrm{Na}$ and ${ }^{27} \mathrm{Al}(\mathrm{n}, \mathrm{p})^{27} \mathrm{Mg}$ direct reactions, beta decay to excited states of ${ }^{24} \mathrm{Mg}$ and ${ }^{27} \mathrm{Al}$ respectively. These excited states then emitted gamma rays as the nuclei de-excite to their respective ground states. The gamma rays are detected and counted. From their numbers the neutron yield is determined.

The DT neutron yield, $\mathbf{Y}_{\mathbf{n}}$, as measured by counting gamma rays in the HPGe detector is given by the equation:

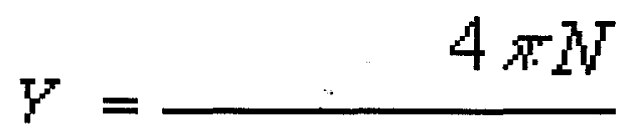

Where $\Omega$ is the solid angle of the aluminum sample, $\mathbf{n}$ is the number density of aluminum, $\sigma$ is the nuclear cross section for $14.1 \mathrm{MeV}$ neutrons and ${ }^{\lambda}$ is the thickness of the aluminum sample. $\beta(\mathbf{E})$ is the efficiency of the HPGe detector at the gamma ray energy of interest and $\lambda$ is the decay constant for ${ }^{24} \mathrm{Na}$ or ${ }^{27} \mathrm{Mg} . \mathbf{T}_{\mathbf{w}}$ is the "wait time" between activation of the sample and the time when counting begins and $\mathbf{t}_{c}$ is the gamma ray counting time. $\mathbf{N} \gamma$ is the number of gamma rays detected by the HPGe and $\mathbf{R}(\mathbf{E})$ is the gamma ray re-absorption coefficient for aluminum.

Three gamma ray peaks are prominent in the gamma ray energy spectrum. They are produced by two nuclear reactions, which lead to the decay of ${ }^{24} \mathrm{Mg}$ and ${ }^{27} \mathrm{Al}$. The decay scheme for ${ }^{24} \mathrm{Mg}$ is shown below. 
DT neutron yield measurements using neutron activation of aluminuhttp://physics.geneseo.edu/backgro..._neutron_yield_measurements_us.htm

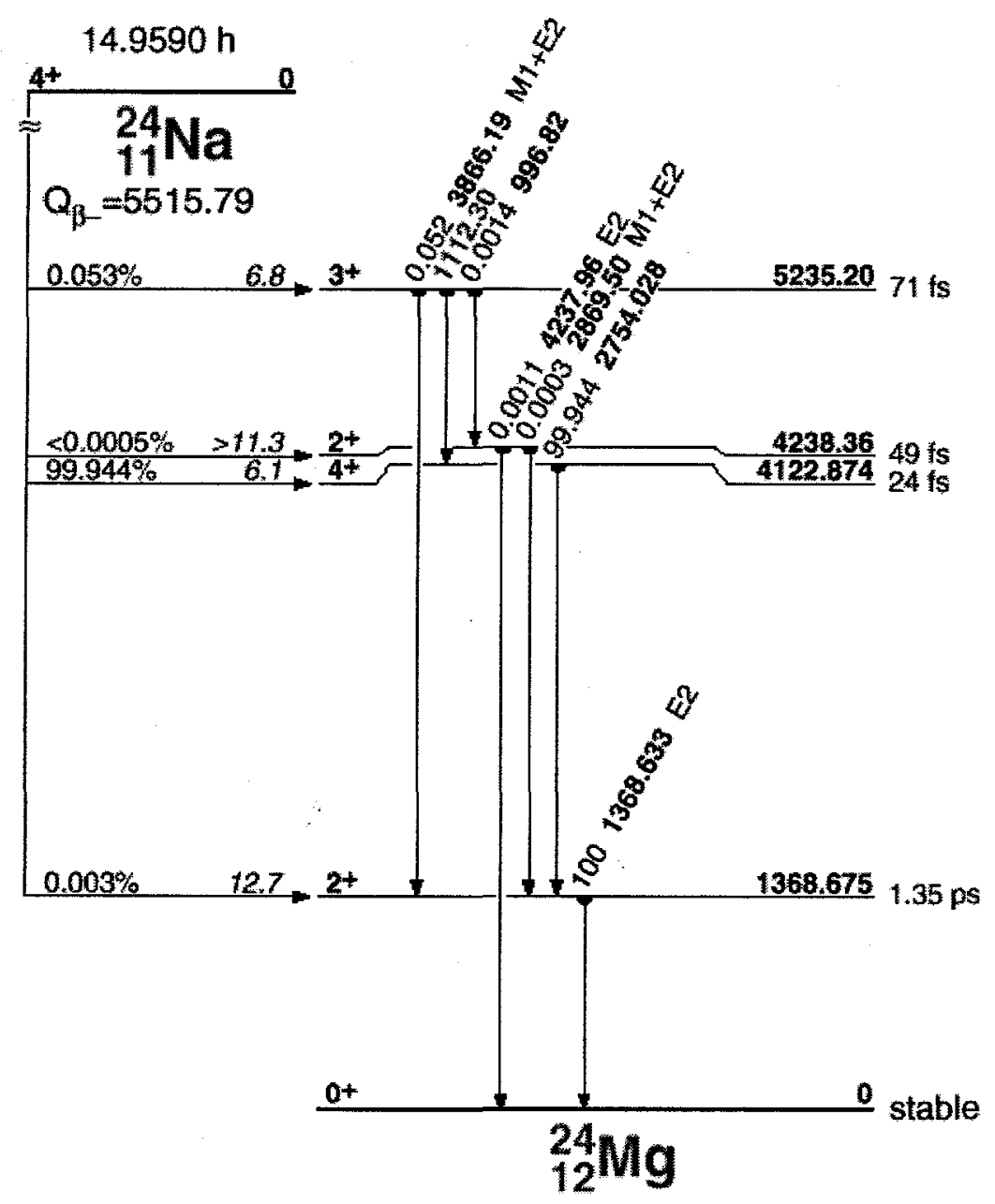

As shown above the ${ }^{24} \mathrm{Na}$ beta decay feeds into the second excited state of ${ }^{24} \mathrm{Mg} 99.944 \%$ of the time. The transition from the second to the first excited state of ${ }^{24} \mathrm{Mg}$ emits a $2.754 \mathrm{MeV}$ gamma ray $99.944 \%$ of the time. Subsequently, the first excited state de-excites $100 \%$ of the time to the ground state, emitting a $1.368 \mathrm{MeV}$ gamma ray making this transition a good indicator of the measure of activation of the aluminum sample. However the efficiency of the high purity germanium (HPGe) detector, used in these measurements, has a low detection efficiency of $2.7 \%$ at $1.368 \mathrm{MeV}$. The gamma ray detection efficiency as a function of energy for the HPGe well detector was measured using a 9 line calibrated gamma ray source at 10 well depths. The calibration curve at $1 \mathrm{~cm}$ from the bottom of the well is shown below. The full set of efficiency curves for all 10 depths are not shown here. 
DT neutron yield measurements using neutron activation of aluminuhttp://physics.geneseo.edu/backgro..._neutron_yield_measurements_us.htm

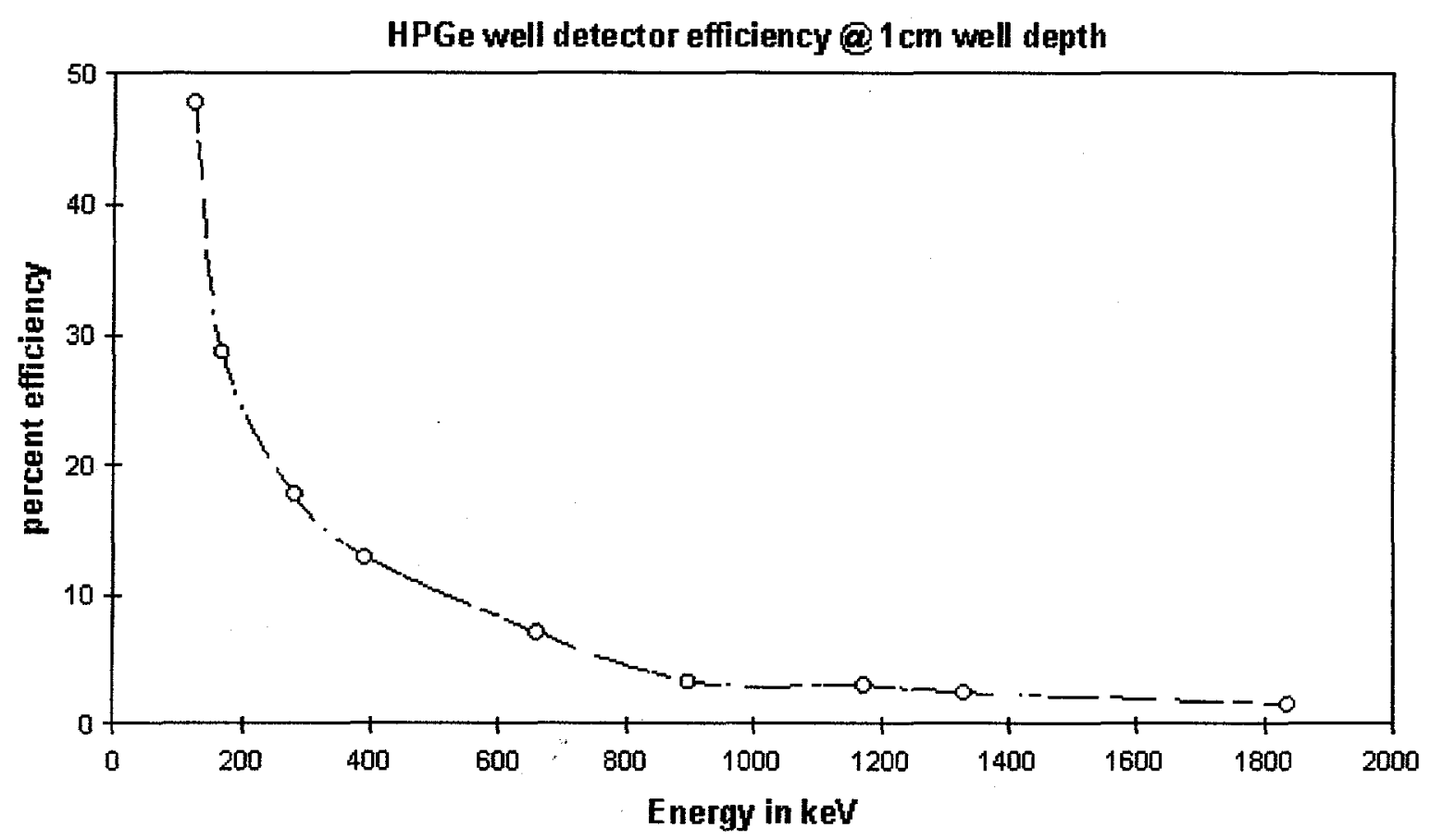

At higher gamma ray energies the detection efficiency drops further. This makes it impractical to use higher energy transitions, such as the $2.754 \mathrm{MeV}$ gamma ray in ${ }^{24} \mathrm{Mg}$ in counting measurements with our detector. In contrast, the efficiency is relatively good near $0.7 \mathrm{MeV}$, approximately $7 \%$. However, the gamma ray background is large and the signal to noise ratio is poor. Our project showed that the gamma ray background at $0.843 \mathrm{MeV}$ is low enough to make a good measurement with reasonable counting statistics.

The production of the $0.843 \mathrm{MeV}$ gamma is shown below in the level diagram for ${ }^{27} \mathrm{Al}$. The beta decay of ${ }^{27} \mathrm{Mg}$ feeds the first and second excited states of ${ }^{27} \mathrm{Al}$. These states de-excite and emit 0.843 and $1.014 \mathrm{MeV}$ gamma rays with branching fractions of $71 \%$ and $29 \%$ respectively. 


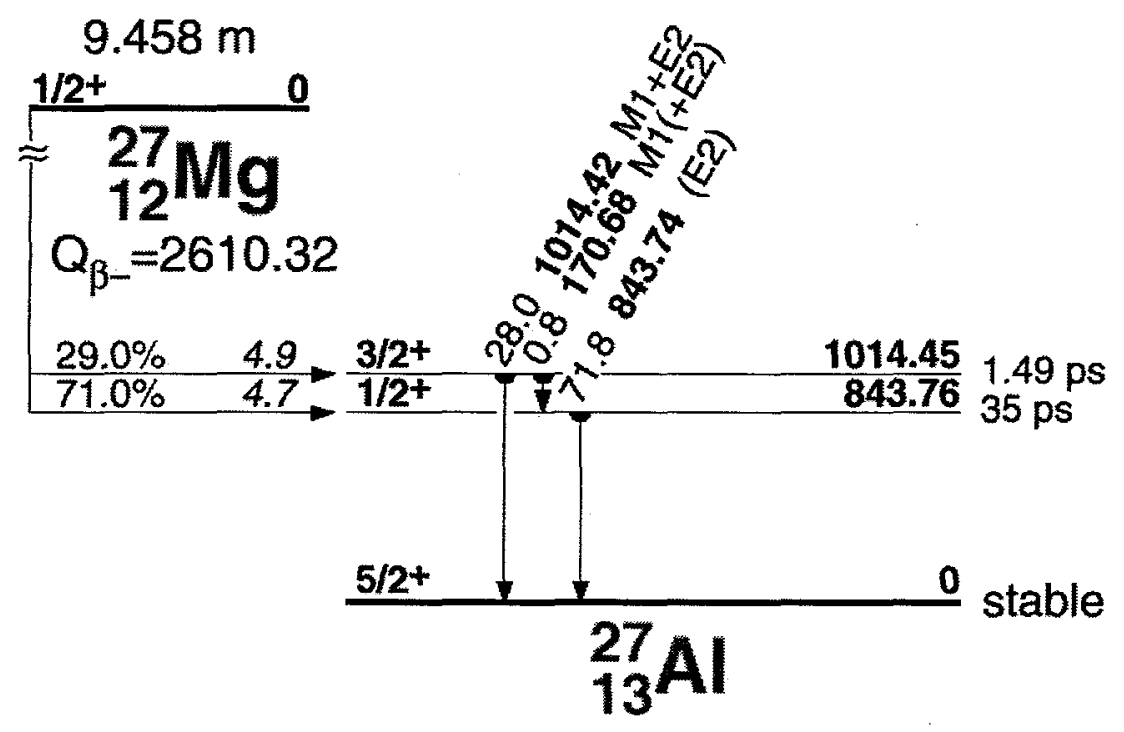

Shown in the next figure is a typical spectrum. The good signal to noise ratio for this gamma peak, coupled with a reasonable detector efficiency, favorable branching fraction and the 9.5 minute half-life made this the best choice for a neutron yield measurement. Due to the physical limitation of the aluminum sample size and half-life of ${ }^{27} \mathrm{Mg}$, yields of less than $10^{8}$ neutrons produced poor gamma counting statistics for times greater than 45 minutes which is the maximum time allowed between experimental events. 


\section{Gamma ray spectrum}
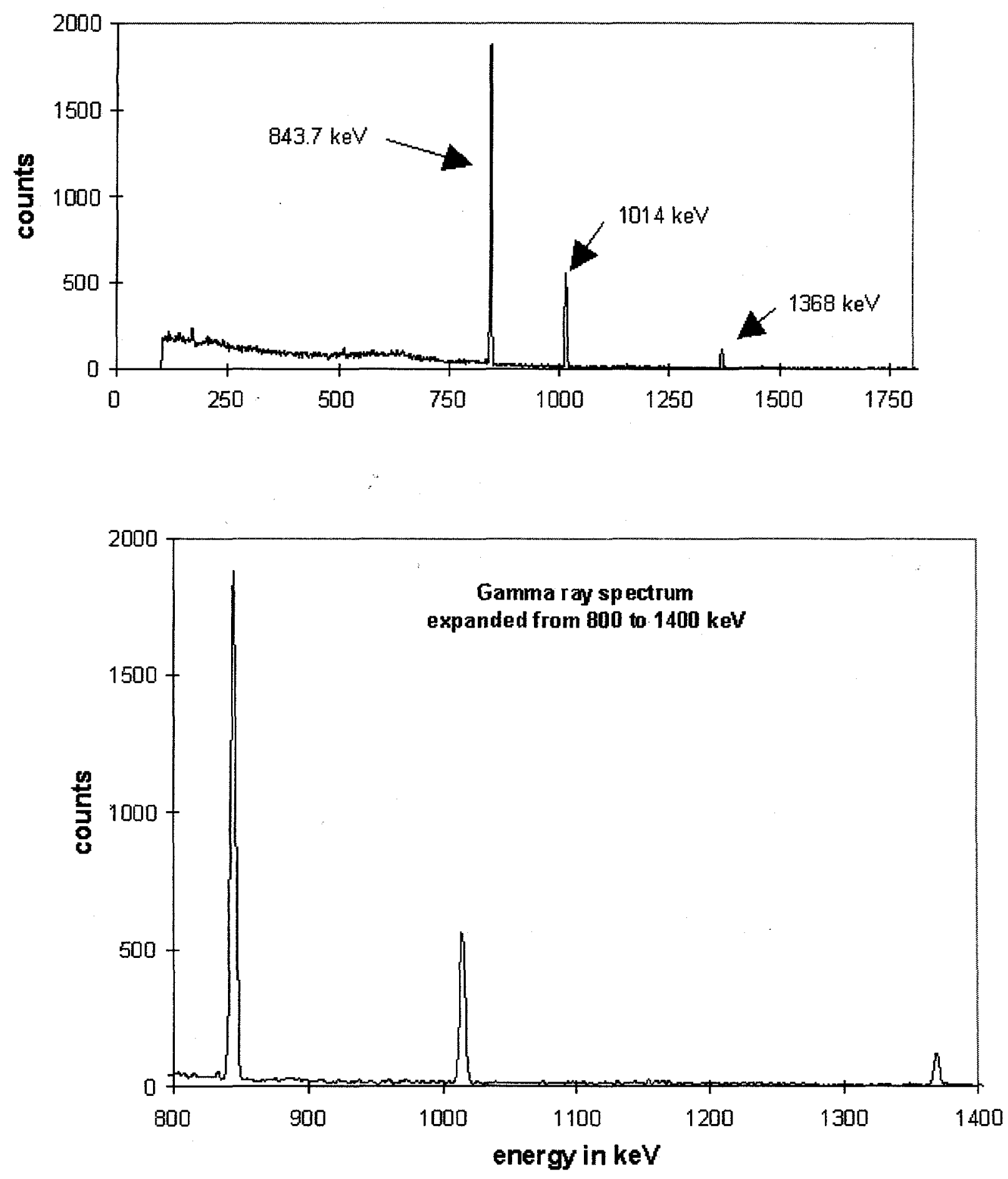

The sensitivity of the aluminum activation method was modified to cover a large dynamic neutron yield range. Some of the factors are fixed by nature and the detector, such as the neutron capture cross section, the half life, the efficiency of the HPGe detector, and the branching ratio of the gamma ray transitions in the decay products. Others could be changed, such as the radial position, mass or type of the activation 
sample and the counting time. The neutron threshold energy is also important and must be high enough to exclude thermal or low energy scattered neutrons. Shown below is a plot of the neutron reaction cross section for the ${ }^{27} \mathrm{Al}(\mathrm{n}, \mathrm{x})$ reactions.

\section{Reaction Cross Sections}

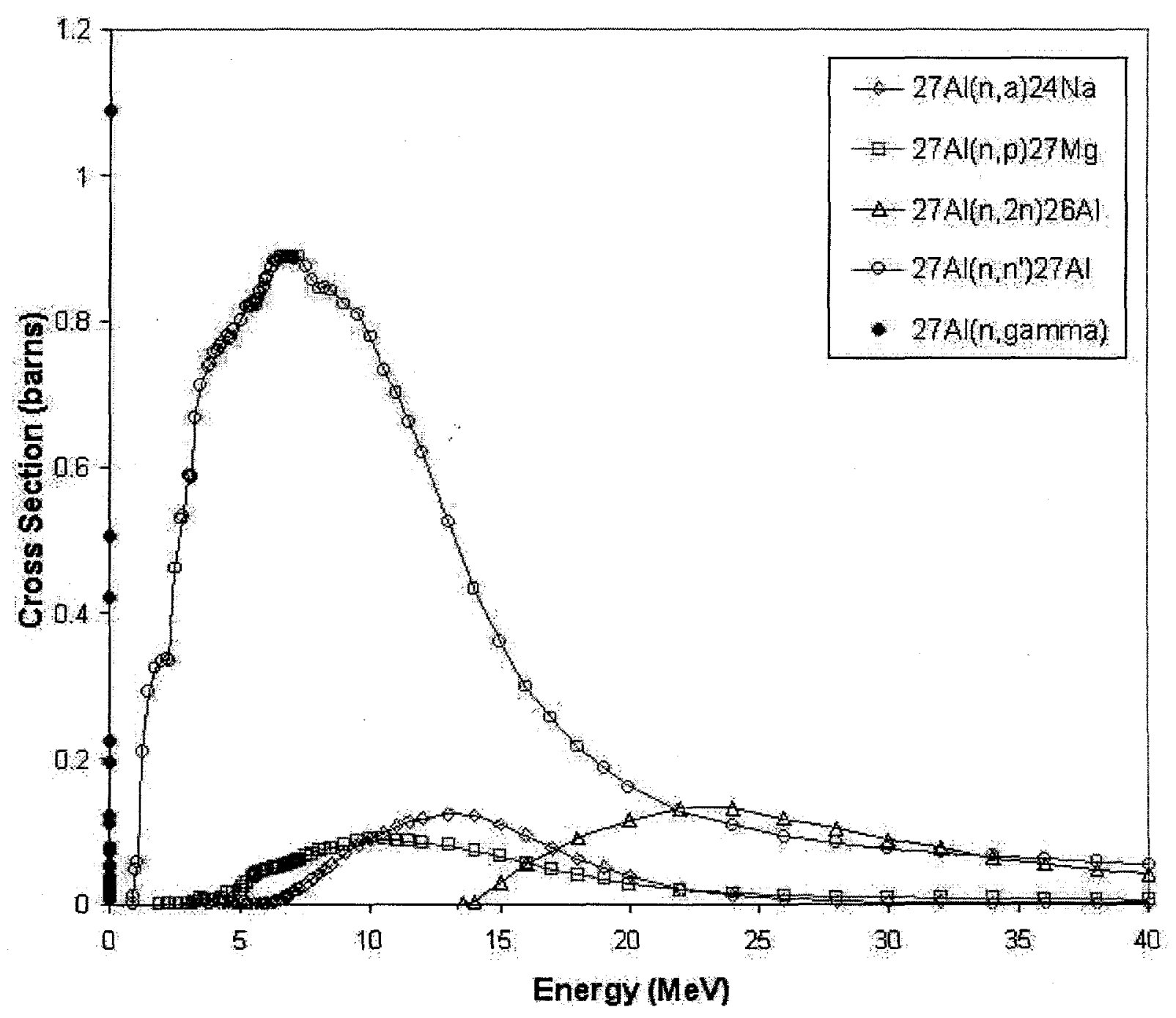

Note that the cross section for neutron capture in the ${ }^{27} \mathrm{Al}(\mathrm{n}, \alpha){ }^{24} \mathrm{Na}$ reaction at $14.1 \mathrm{MeV}$ is 121.2 millibarns. Compare this to 72.3 millibarns for the ${ }^{27} \mathrm{Al}(\mathrm{n}, \mathrm{p})^{27} \mathrm{Mg}$ reaction. Furthermore the $\mathrm{n}, \mathrm{n}$ ' reaction is prompt and does not play a role in our measurement time scale. 
DT neutron yield measurements using neutron activation of aluminunttp://physics.geneseo.edu/backgro..._neutron_yield_measurements_us.htm

\begin{tabular}{|c|c|c|}
\hline Reaction & Cross Section at $14.1 \mathrm{MeV}$ & Halflife \\
\hline $27 \mathrm{Al}(\mathrm{n}, \alpha) 24 \mathrm{Na}$ & 0.123 barns & $15 \mathrm{hrs}$ \\
\hline $27 \mathrm{Al}(\mathrm{n}, \mathrm{p}) 27 \mathrm{Mg}$ & 0.073 barns & $9.5 \mathrm{hrs}$ \\
\hline $27 \mathrm{Al}(n, 2 n) 26 \mathrm{Al}$ & 0.004 barns & 740,000 yrs \\
\hline $27 \mathrm{Al}\left(n, n^{\prime}\right) 27 \mathrm{Al}$ & 0.433 barns & \\
\hline
\end{tabular}

The aluminum activation experiment used the $843 \mathrm{KeV}$ gamma ray counting measurement to determine the neutron yield from DT reactions. These measurements were then compared to the yields measured with the copper activation method. A comparison of aluminum method vs. the copper method is shown below for 40 Omega shots.

The measurements reveal a very strong correlation between the two methods. The absolute yield produced by the aluminum method is consistent with the copper method by to $1 \%$.

\section{Aluminum Activation vs. Copper Activation}

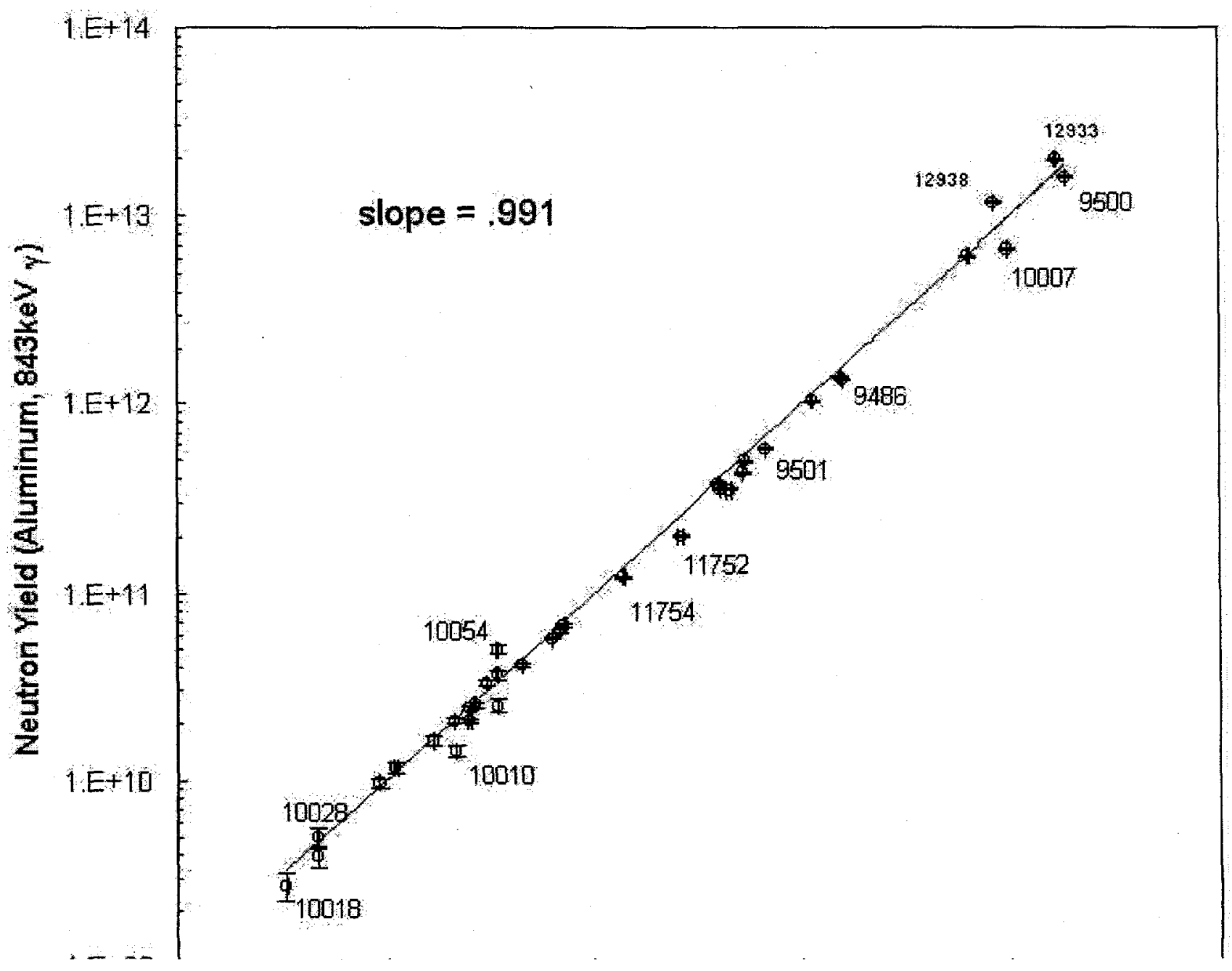


DT neutron yield measurements using neutron activation of aluminuhttp://physics.geneseo.edu/backgro..._neutron_yield_measurements_us.htm 